\title{
Preconceito racial entre crianças da educação infantil: revisitando Clark \& Clark (1947)
}

\author{
Racial Prejudice among Children of Early Childhood Education: \\ Revisiting Clark \& Clark (1947)
}

\section{Prejuicio racial entre niños de la educación infantil: revisitando Clark \& Clark (1947)}

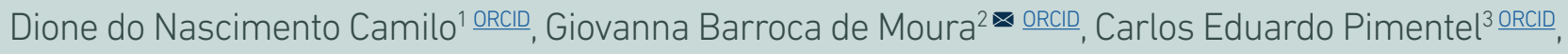

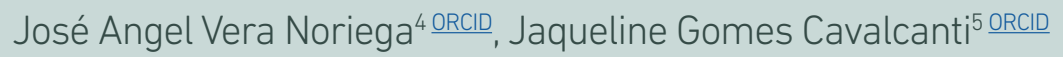

\author{
${ }^{2}$ Universidade Estadual Vale do Acaraú (UVA) \\ 13 Universidade Federal da Paraíba \\ ${ }^{4}$ Centro de Investigación em Alimentación y Desarrollo \\ ${ }^{5}$ Centro Universitário UNIESP \\ Brasil
}

Fecha correspondencia:

Recibido: febrero 1 de 2019.

Aceptado: enero 17 de 2020.

Forma de citar:

Camilo,N. D., Moura, B. G., Pimentel,

C. E., Vera Noriega, J.A., \& Cavalcanti,

J. G. (2020). Preconceito racial

entre crianças da educação infantil:

revisitando Clark \& Clark (1947). Rev.

CES PSico, 13(2), 32-45.

\section{Open access}

(c) Copyright

Licencia creative commons

Ética de publicaciones

Revisión por pares

Gestión por Open Journal System

DOI: http://dx.doi.org/10.21615/

cesp. 13.2 .3

ISSN: 2011-3080

\section{Resumo}

0 preconceito racial entre crianças é um tema sumamente importante para explorar a gênese desse vírus social. No entanto, poucos pesquisadores no Brasil se interessaram pela temática. 0 objetivo principal desse trabalho é replicar o experimento clássico de Clark e Clark (1947). Participaram 99 crianças paraibanas, negras (51) e brancas (48). Cerca de 86,9\% das crianças escolheram a boneca branca para brincar; $78,8 \%$ das crianças consideram a boneca branca como a boa; 76,8\% escolheram a boneca negra como má; $92,9 \%$ das crianças escolheram boneca de branca como a legal; $84,8 \%$ das crianças disseram que a boneca branca se parece com ela; $85,9 \%$ disseram que fariam atividade para nota com a boneca branca. Os principais resultados denunciam o preconceito de cor em crianças no ambiente escolar. Espera-se que novos estudos ressaltem a temática do preconceito racial entre crianças escolares, destacando o papel da mídia, da família e da escola.

Palavras-chave: Educação Infantil, Preconceito Racial, Relações Intergrupais.

\section{Abstract}

The racial prejudice among children is an extremely important issue in exploring the genesis of this social virus. However, few researchers in Brazil were interested in the subject. The main objective of this paper is to replicate the classic Clark and Clark's experiment (1947). Ninety-nine children from Paraíba, black (51) and white (48) participated. About $86.9 \%$ of the children chose the white doll to play with; $78.8 \%$ of the children considered the white doll as the good one; $76.8 \%$ chose the black doll as the bad one; $92.9 \%$ of the children considered the white doll as the nice one; $84.8 \%$ of the children indicated that the white doll looks like them; $85.9 \%$ stated that 
Sobre los autores:

1. Graduada em Pedagogia pela Universidade Federal da Paraíba.

2. Doutoranda em Psicologia Social. Mestre em Cooperação al Desarrolho. Especialista em Saúde Mental, Bacharelado em Pedagogia. Licenciatura em Psicologia.

3. Doutor em Psicologia Social, do Trabalho e das Organizações. Coordenador do Laboratório de Psicologia da Mídia. Professor Adjunto do Curso de Psicologia e da Pós-Graduação em Psicologia Social da Universidade Federal da Paraíba.

4. Doutor em Psicologia Social. Pesquisador e professor do Centro de Investigação em Alimentação y Desarrolho.

5. Doutor em Psicologia Social. Graduada em Psicologia. Atualmente é docente do curso de Psicologia do Centro Universitário UNIESP. they would do academic activity with the white doll. The main results denounce the color prejudice in children in the school environment. More studies are expected to highlight racial prejudice among school-age children, highlighting the role of the media, the family and the school.

Keywords: Early Childhood Education, Racial Prejudice, Intergroup Relations.

\section{Resumen}

El prejuicio racial entre niños es un tema sumamente importante para explorar la génesis de este virus social. Sin embargo, pocos investigadores en Brasil se han interesado por la temática. El objetivo principal de este trabajo es replicar el experimento clásico de Clark y Clark (1947) sobre la génesis y el desarrollo de la identificación racial en función de la autoconciencia en los niños negros ${ }^{1}$. Participaron 99 niños paraibanos, negros (51) y blancos (48). Cerca de $86,9 \%$ de los niños eligieron la muñeca blanca para jugar; $78,8 \%$ de los niños consideran la muñeca blanca como la buena; 76,8\% eligió la muñeca negra como mala; $92,9 \%$ de los niños eligieron muñeca blanca como la agradable; $84,8 \%$ de los niños señaló que la muñeca blanca se parece a ellos; $85,9 \%$ afirmó que realizarían actividad académica con la muñeca blanca. Los principales resultados denuncian el prejuicio de color en niños en el ambiente escolar. Se espera que más estudios resalten los prejuicios raciales entre los niños en edad escolar, destacando el papel de los medios de comunicación, la familia y la escuela.

Palabras clave: Educación Infantil, Prejuicio Racial, Relaciones Intergrupales.

\section{Introdução}

"Eu tenho um sonho.

O sonho de ver meus filhos julgados por sua personalidade, não pela cor de sua pele".

(Martin Luther King)

O sonho do grande líder negro ainda é premente nos dias hodiernos e como na sociedade estadunidense, também no Brasil. A sociedade brasileira é formada por negros, brancos, índios, entre outros. Somos um povo miscigenado não só na cor, mas também na cultura, a diversidade está presente em todos os cantos do nosso país e mesmo assim não é raro sabermos de casos de discriminação e preconceito que ocorrem pelos mais diversos motivos.

Muitos estudiosos internacionais da temática do preconceito racial afirmam que desde muito cedo na vida o indivíduo é capaz de se definir em termos de pertença a grupos raciais e mostrar-se ativo na aprendizagem e na compreensão desta inserção (Aboud, 1998; Allport, 1954; Brown, 2010; Hirschefeld, 1996; Katz, 1976; Ramsey, 1987; Tajfel, 1978).

Destaca-se, o estudo de dois psicólogos norte-americanos, Clark e Clark (1947), sobre a gênese e desenvolvimento de identificação racial como função da autoconsciência em crianças negras, os quais participaram crianças negras entre 4 a 6 anos. Foram usadas quatro bonecas (duas eram negras e duas eram brancas). As crianças eram solicitadas a responder 9 perguntas, escolhendo uma das bonecas. Quatro

1. O uso da palavra negro neste artigo é detrimento ao estudo original realizado por Clarck e Clarck em 1947 e não tem nenhuma conotação depreciativa Entretanto, o termo "negro" será usado para se referir à população negra afrodescendentes. 
Pág 34

De acordo com os principais resultados da pesquisa realizada por Clark e Clark (1947), 67\% preferiam a boneca branca para brincar; $59 \%$ diziam que as bonecas brancas eram as bonitas; 60\% diziam que as bonecas brancas tinham uma cor bonita; e, por outro lado, 50\% das crianças diziam que as bonecas negras pareciam más. No entanto, sendo o Brasil um país tão miscigenado, existe preconceito racial entre crianças neste país? questionamento foram pensadas para revelar preferências (dê-me a boneca que você gostaria de brincar, a mais bonita, a que parece má, a que é de uma cor bonita); três para indicar conhecimento de diferenças raciais (dê-me a boneca que parece uma criança branca, dê-me a boneca que parece com uma criança de cor ${ }^{2}$, dê-me a boneca que parece uma criança negra); uma para mostrar auto identificação (dê-me a boneca que parece com você). A última pergunta, foi considerada uma pergunta realizada no estudo de França e Monteiro (2011): com qual você faria atividades para nota? Resultados desta pesquisa concluíram que, na primeira infância, as crianças já se definem em termo da pertença a um grupo racial. Foi verificada ainda alta preferência pela boneca branca, indicando que o preconceito já estava disseminado nas crianças.

De acordo com os principais resultados da pesquisa realizada por Clark e Clark (1947), 67\% preferiam a boneca branca para brincar; 59\% diziam que as bonecas brancas eram as bonitas; $60 \%$ diziam que as bonecas brancas tinham uma cor bonita; e, por outro lado, $50 \%$ das crianças diziam que as bonecas negras pareciam más. No entanto, sendo o Brasil um país tão miscigenado, existe preconceito racial entre crianças neste país?

Há nível nacional, o preconceito racial entre crianças é tema de poucas pesquisas. Uma das mais recentes foi realizada pela pedagoga Paré (2000), que realizou uma pesquisa em escola pública e privada com alunos negros. A pesquisadora observou em seus resultados, alto índice de evasão e repetência em estudantes negros. Detectou também, baixa autoestima do aluno negro vinculado ao seu desempenho escolar.

Podemos também destacar a pesquisa de Fernandes, Almeida e Nascimento (2008) em que participaram 19 crianças de 5 a 8 anos de idade, todas brancas do interior de Sergipe. Nesta pesquisa, foi solicitado às crianças que desenhassem duas crianças: uma criança branca e uma criança negra. Através dos desenhos as crianças responderam a questões sobre escolhas e preferências em relação a cinco categorias: riqueza, beleza, inteligência, proximidade e contato. Os resultados desta pesquisa revelaram que a categoria beleza foi apontada por $62,75 \%$ das crianças como qualidade, em maior grau, de pessoas brancas; 79,5\% das crianças escolheram o alvo branco como mais rico e, em se tratando do critério inteligência, em 73,5\% dos casos, a indicação esteve voltada para o alvo branco, 79,5\% das escolhas para brincar dirigidas ao alvo branco e $80 \%$ para adotar como irmão o branco. A criança negra foi fortemente rejeitada.

Um estudo semelhante foi desenvolvido por França e Monteiro (2002) com 238 crianças de ambos os sexos e com diferente grupo racial, entre 5 a dez anos. A amostra foi retirada da escola pública e privada da cidade de Aracaju. 0 objetivo desta pesquisa foi analisar a identidade racial de crianças brancas, mulatas e negras. Os resultados demonstraram que as crianças negras não gostam e não aceitam ser assim. Este estudo ainda demonstrou à preferência dominante a criança branca. E verificaram que cerca de $69 \%$ das crianças preferem fazer atividade para nota com as crianças de cor branca. No mesmo direcionamento, outra pesquisa que merece destaque é o estudo de Silva, Pereira e Camino (2002). Esses pesquisadores observaram que $57 \%$ das crianças morenas se auto categorizaram como brancas e que $78 \%$ das crianças negras se auto categorizaram como morenas. 
Pág 35

Mesmo que no Brasil muitas pessoas neguem que são preconceituosas elas acusam o outro como preconceituoso (Turra \& Venturi, 1995). 0 preconceito no Brasil é uma realidade, apesar da diversidade étnica existente no país, muitos brasileiros praticaram ou já sofreram algum tipo de discriminação.
Acerca desses dois últimos estudos supracitados, convém destacar que os autores não explicam o que trata o termo "mulata" ou "morena", bem como em que se diferencia da categoria negra. A despeito disso, tais nomenclaturas não têm sido recomendadas contemporaneamente por estudos recentes, consideradas, formas de branqueamento (Silva, 2018; Weschenfelder \& Silva, 2018).

Por fim, outro estudo relacionado, realizou entrevistas com 161 crianças de 9 a doze anos de idade estudantes de escola pública. Foram utilizadas figuras de crianças brancas, morenas e negras e verificaram-se que as crianças atribuíam mais características positivas, como beleza e capacidade de comunicação, às figuras brancas, sendo que às figuras negras foram atribuídas características negativas como falta de honestidade (Máximo, Larrain, Nunes, \& Lins, 2012). Os autores verificaram uma tendência ao branqueamento, observando que somente $6,3 \%$, das crianças entrevistadas, escolheram figuras negras como parecidas com elas, sendo $17,4 \%$ crianças consideradas brancas, $52,8 \%$ de morenas e $29,8 \%$ de negras.

\section{Preconceito racial no Brasil}

Em psicologia social, o preconceito é "uma atitude negativa dirigida a um grupo e aos que dele fazem parte" (Rodrigues, Assmar, \& Jablonski, 2012, p. 199). Mesmo que na atitude existam o componente afetivo (sentimentos), comportamental (tendência a agir) e cognitivo (crenças a respeito), quando se trata do preconceito se está referindo especificamente ao aspecto afetivo. É uma atitude hostil por alguém representar um grupo específico, que é desvalorizado na sociedade, como o grupo dos negros (Allport, 1954; Rodrigues et al., 2012) especificamente trata-se de uma antipatia para alguém que pode se dirigir a um indivíduo por fazer parte deste grupo desvalorizado socialmente ou para o grupo (Allport, 1954). Termos relacionados ao preconceito são o estereótipo, a discriminação e o racismo. 0 estereótipo é a base cognitiva do preconceito; a discriminação consiste no comportamento, como evitar andar com um negro ou gay (Pérez-Nebra \& Jesus, 2011); e o racismo é a discriminação cuja base é a cor da pele (APA, 2015). De acordo com Nelson (2009) uma das primeiras medidas de preconceito entre crianças foi a tarefa da preferência pela boneca desenvolvida por Clark e Clark (1947).

Mesmo que no Brasil muitas pessoas neguem que são preconceituosas elas acusam o outro como preconceituoso (Turra \& Venturi, 1995). 0 preconceito no Brasil é uma realidade, apesar da diversidade étnica existente no país, muitos brasileiros praticaram ou já sofreram algum tipo de discriminação.

Mas o que acontece no Brasil é uma discriminação disfarçada, os meios de comunicação entre eles à televisão colocam o negro sempre numa posição de inferioridade, além disso, os brinquedos, os livros didáticos, enaltecem o branqueamento como única forma de beleza, caráter e capacidade intelectual (Bento, 2002; Carneiro, 1998; Guimarães, 2004), dessa forma a criança e até mesmo o adulto negro não se identifica com a sua raça e sofre rejeitando a sua origem racial e negando sua identidade. Além dessas formas de preconceito mais amenas e indiretas, as quais são explicadas por teorias contemporâneas como as do racismo moderno, simbólico, aversivo, ambivalente, sutil ou cordial (Lima \& Vala, 2004), no Brasil e no mundo se verificam ainda as formas tradicionais, flagrantes, como as manifestações de torcedores contra o goleiro Aranha e diversos outros atos preconceituosos no mundo do futebol. 
Pág 36

A sociedade juntamente com a escola tem a tarefa de combater o preconceito e ensinar a criança a lidar com a diversidade e pluralidade apresentada no espaço onde ela está inserida, para cumprir esse papel a escola pode usar várias estratégias e atividades diferenciadas que ajudem os alunos a conviver e respeitar as diferenças.
Além disso, ainda há o preconceito do negro contra o negro. Segundo Frantz Fanon (2008) há mil formas de fazer o negro odiar sua cor, pois, a cultura de branqueamento existente hoje pode influenciar a cultura negra, no modo de vestir, na religião, no cabelo, nas superstições. Isso acontece porque o negro passa a ver sua autoimagem de forma negativa e uma imagem positiva do homem branco, dessa forma ele busca assemelhar-se a imagem que julga ser perfeito. Roland (2001, p.19) ressalta que: "0 sistema propõe o ideal de branqueamento para os indivíduos negros. Não é a toa que a população negra se classifica de diversas maneiras e essa múltipla classificação resulta numa população fragmentada".

Mas onde será que o preconceito racial mais ocorre? Será que o preconceito racial também está presente na escola?

\section{A necessidade de pluralidade cultural na escola}

Os Parâmetros Curriculares Nacionais (PCNs) introduziu no Brasil a temática Pluralidade Cultural com o objetivo de abordar às relações sociais discriminatórias, que excluem e permeiam a sociedade, levando a discussão sobre as práticas de racismo na sala de aula, com o fim de superar o preconceito e atitudes discriminatórias (Secretaria de Educação Fundamental de Brasil, 1997). Além do PCNs, a lei de Diretrizes e Bases da Educação Nacional ( $n^{\circ}$ 9.394/96) também reconhece a importância dos valores para a educação escolar, tendo como objetivo a formação da cidadania, incluindo como finalidade da educação valores e princípios que são de relevante importância ao ambiente escolar, exonerando qualquer forma de preconceito ou discriminação.

Como podemos observar a sociedade juntamente com a escola tem a tarefa de combater o preconceito e ensinar a criança a lidar com a diversidade e pluralidade apresentada no espaço onde ela está inserida, para cumprir esse papel a escola pode usar várias estratégias e atividades diferenciadas que ajudem os alunos a conviver e respeitar as diferenças. Nesse sentido, "a educação se tornará mais coerente e eficaz se formos capazes de explicitar seus valores, ou seja, se desenvolvermos um trabalho reflexivo que esclareça as bases axiológicas da educação" (Aranha, 2002, p.119).

\section{0 preconceito entre as crianças da educação infantil}

De acordo com Levy, Rosenthal e Herrera-Alcazar (2010) o racismo aparece desde idade muito precoce, por volta de 5 anos, o que indica que a criança quando entra na escola já traz consigo o preconceito. Este dado é corroborado por Brown (2010) que destaca componentes de preconceito em crianças entrevistadas com apenas 4 anos de idade. Quando a criança passa a frequentar a escola, ela se depara com uma diversidade enorme de culturas, raças, credos, entre outros. Ao observar esse mundo a criança passa exteriorizar o que apreendeu com a sua família e busca pessoas consideradas familiares, ou seja, que tenham características similares aos dela.

É durante a convivência na escola que a criança percebe que as outras pessoas possuem características diferentes e muitas vezes essa descoberta traz muitos conflitos. Acerca dessa percepção os PCNs ressaltam que no dia a dia da escola se reconhece a diversidade da beleza do ser humano. Pode levar à consciência da unicidade de cada um e da sua qualidade de ser insubstituível e singular (Brasil, 1997).

Além de todos esses conflitos que permeiam o universo da criança, o branqueamento racial no contexto infantil é uma realidade, trata-se da valorização da raça dominante, 
Pág 37

O objetivo principal desse trabalho é replicar o experimento clássico de Clark e Clark (1947) com o fim de verificar se seus resultados se repetem numa amostra de crianças da educação infantil, especificamente de Alagoa Grande, município da Paraíba (Brasil). Busca-se, pois, verificar se existe o preconceito na educação infantil. Especificamente, busca-se verificar a preferência de crianças em relação à cor da pele, considerando bonecas negras e brancas. ou seja, do homem branco. De acordo com essa ideia quanto mais clara a cor da pele maior sua beleza, melhor o seu caráter e sua capacidade intelectual (Carneiro, 1998; Bento, 2002).

O brinquedo demonstra o que vivemos na vida real, um total jogo de aparência que tem como objetivo maquiar o preconceito existente no Brasil, as bonecas são o maior exemplo disso, a Barbie a boneca mais vendida no mundo mostra traços europeus e um estereótipo diferentes da maioria das crianças brasileiras, formadas em sua maioria por pardos e negros.

O Brasil detém $86 \%$ do mercado de "bonecas fashion" (produto novo para um público muito exigente, decidido, versátil e descolado e "plugadas" em tecnologia) e 78\% do mercado de produtos de consumo infantil para meninas (Garcia, 2005). A cada segundo, duas Barbies são vendidas no mundo. Em relação aos bonecos negros: existe um processo afetivo e de identificação das crianças com os brinquedos. Os bonecos negros na escola indicam que a escola respeita a diversidade racial que se observa no nosso país (Junior, Bento, \& Carvalho, 2012).

Tendo em vista a importância de tudo que foi anteriormente explicitado, o objetivo principal desse trabalho é replicar o experimento clássico de Clark e Clark (1947) com o fim de verificar se seus resultados se repetem numa amostra de crianças da educação infantil, especificamente de Alagoa Grande, município da Paraíba (Brasil). Busca-se, pois, verificar se existe o preconceito na educação infantil. Especificamente, busca-se verificar a preferência de crianças em relação à cor da pele, considerando bonecas negras e brancas.

\section{Método}

\section{Participantes}

A pesquisa foi realizada em duas instituições de educação infantil: pública e privada, todas localizadas em Alagoa Grande no brejo paraibano, Brasil. Participaram 99 crianças, sendo 52 do sexo masculino e 47 do sexo feminino, 40 da escola particular e 59 da escola pública, com idades entre 4 e 6 anos. Dessas, 48 são brancas e 51 negras.

\section{Materiais e instrumento}

Foram utilizadas 4 bonecas de pano adquiridas na região que se desenvolveu esta pesquisa, sendo 2 bonecas brancas e 2 bonecas negras, estas bonecas (de ambos os sexos) podem ser vistas na Figura 1.

Seguindo, o proposto por Clark e Clark (1947) foram realizadas as seguintes solicitações: 1) me dê à boneca que você gosta de brincar; 2) me dê à boneca boa; 3) me dê à boneca má; 4) me dê à boneca que tem uma cor legal; 5) me dê à boneca que parece com uma criança branca; 6) me dê à boneca que parece com uma criança de cor; 7) me dê à boneca que parece uma criança negra e 8) me dê à boneca que parece com você. Foi considerada também uma pergunta realizada no estudo de França e Monteiro (2011): com qual você faria atividades para nota?

O experimentador fez as perguntas às crianças numa sala adequada para isso. 0 experimentador apresentou para cada criança as duas bonecas e uma ficha impressa, na qual anotou as respostas das crianças assim como a sua cor da pele (segundo a percepção do experimentador), a idade, o tipo de escola e a série. 


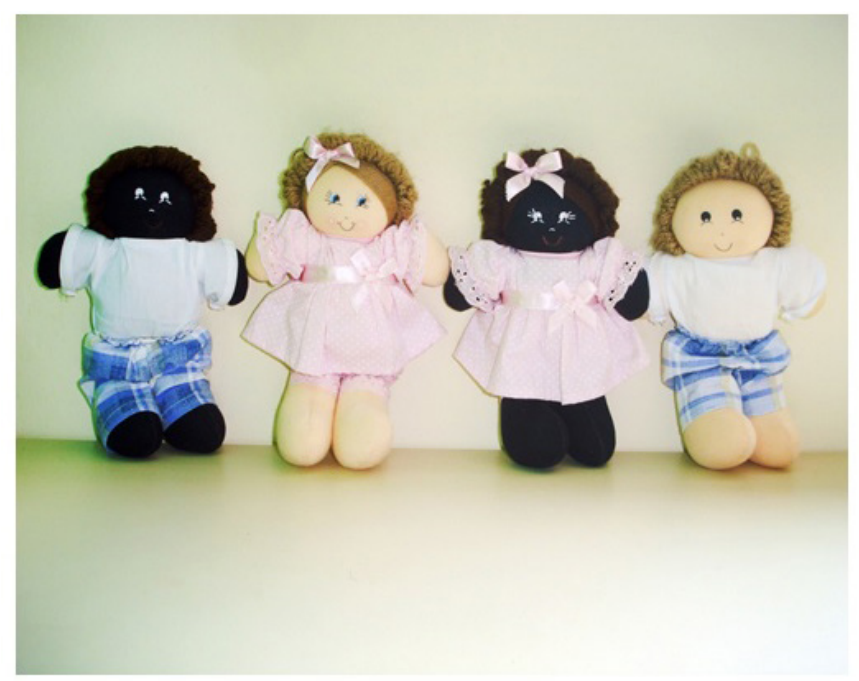

Figura 1. Bonecas utilizadas no experimento.

\section{Procedimentos metodológicos}

Inicialmente foram realizadas visitas nas escolas, com a finalidade de obter informações acerca da quantidade de alunos da educação infantil. Em seguida, realizou-se um contato com a direção das instituições escolares com o propósito de obter a autorização dos gestores para a realização da pesquisa.

Com a autorização da direção para a realização deste estudo, tendo como princípio a participação voluntária, foram explicitados os objetivos pertinentes ao estudo, além da garantia do anonimato e confidencialidade das respostas proferidas pelos participantes, uma vez que os dados foram tratados em seu conjunto e em sigilo.

Quanto à aplicação da tarefa do experimento, esta se deu de forma individual, nas próprias dependências da escola pesquisada, sob a responsabilidade da pesquisadora devidamente treinada, autora deste artigo, que apresentou individualmente bonecos brancos e negros para as crianças.

\section{Aspectos Éticos}

Para esta pesquisa foi inicialmente solicitado à direção das escolas para o desenvolvimento da pesquisa. Tomando por base o que preconiza as Resoluções 466/2012 e 510/2016, posteriormente foram enviados Termos de Consentimento Livre e Esclarecido (TCLE) aos pais, juntamente com uma carta explicativa acerca da pesquisa. As crianças cujos pais consentiram e que quiseram participar foram lhes garantidos o anonimato e o sigilo das informações, assegurando-lhes, ainda, a possibilidade de desistência no tocante à colaboração a qualquer momento do estudo. Com as crianças, inicialmente estabeleceu-se uma boa interação. Foram explicados os objetivos e procedimentos da coleta de dados, de modo a obter o consentimento livre e esclarecido de forma oral.

\section{Digitação e análise dos dados}

Após a coleta dos dados, as respostas referentes ao questionário bio-sóciodemográfico e as respostas fornecidas pelas crianças foram tabuladas no programa Microsoft Office Excel, versão 2003, para em seguida serem processadas no SPSS 18 , com o intuito de analisar a média, frequência e percentual. As diferenças entre os percentuais foram analisadas no Statistics Calculator. 


\section{Resultados e Discussão}

As tabelas que seguem revelam as proporções descritivas de diferenciação (em frequência e porcentagem) entre a preferência frente os brancos e negros na visão das crianças brancas, negras.

Tabela 1. Respostas à tarefa experimental considerando todas as crianças $(N=99)$

\begin{tabular}{|c|c|c|c|c|c|c|}
\hline & \multicolumn{2}{|c|}{ Branca } & \multicolumn{2}{|c|}{ Negra } & \multicolumn{2}{|c|}{ Total } \\
\hline & $N$ & $\%$ & $N$ & $\%$ & $N$ & $\%$ \\
\hline Me dê a boneca que você gosta de brincar & 86 & $86,9 \%$ & 13 & $13,1 \%$ & 99 & $100 \%$ \\
\hline Me dê a boneca boa & 78 & $78,8 \%$ & 21 & $21,2 \%$ & 99 & $100 \%$ \\
\hline Me dê a boneca má & 23 & $23,2 \%$ & 76 & $76,8 \%$ & 99 & $100 \%$ \\
\hline Me dê a boneca que tem uma cor legal & 92 & $92,9 \%$ & 7 & $7,1 \%$ & 99 & $100 \%$ \\
\hline Me dê a boneca que parece com uma criança branca & 96 & $97 \%$ & 3 & $3 \%$ & 99 & $100 \%$ \\
\hline Me dê a boneca que parece com uma criança negra & 3 & $3 \%$ & 96 & $97 \%$ & 99 & $100 \%$ \\
\hline Me dê a boneca que parece uma criança negra & - & - & 99 & $100 \%$ & 99 & $100 \%$ \\
\hline Me dê a boneca que parece com você & 84 & $84,8 \%$ & 15 & $15,2 \%$ & 99 & $100 \%$ \\
\hline Me dê a boneca que você faria atividades para nota & 85 & $85,9 \%$ & 14 & $14,1 \%$ & 99 & $100 \%$ \\
\hline
\end{tabular}

Como pode ser observado na Tabela 1, a partir do questionário realizado e a utilização de bonecas tendo como critérios a preferência das crianças em relação à escolha de brincar, boa, má, cor legal, aparência branca e negra, a que parece com você e a que você escolheria pra fazer atividades para nota. Como pode ser visto na tabela as crianças tiveram uma predileção pela cor branca. Cerca de $86,9 \%$ das crianças escolheram a boneca branca para brincar. Na segunda questão, 78,8\% das crianças consideram a boneca branca boa e apenas $21,2 \%$ afirmaram que a boneca negra é boa. Na questão 3 pode ser observado que 76,8\% das crianças escolheram a boneca negra como sendo má e a boneca branca foi escolhida por $23,2 \%$ das crianças.

Na questão seguinte, 92,9\% das crianças acham a cor branca legal enquanto 7,1\% acham a cor negra legal. A questão me dê uma boneca que parece uma criança de cor foi escolhida por $97 \%$ das crianças que se referiram à boneca negra e $3 \%$ da boneca branca. A penúltima pergunta me dê á boneca que se parece com você foi a mais repensada, mas a maioria $84,8 \%$, se identificou como sendo da cor branca e a última questão também teve como predileção a boneca branca com 85,9\% e a boneca negra com $14,1 \%$.

A questão 7, referente a "Me dê a boneca que parece uma criança negra", 100\% das crianças aludiram a boneca negra, levando a refletir que todas as crianças sabem diferenciar o negro do branco. A penúltima questão, 84,8\% afirmaram que se parecem com a boneca branca. A última pergunta, $85,9 \%$ das crianças responderam que preferiam fazer atividades para nota com as bonecas brancas.

Foram realizados testes estatísticos com o fim de verificar se as diferenças nos percentuais eram estatisticamente significativas. Para isso se utilizou do software Statistics Calculator, especificamente o teste t entre percentis para uma amostra.

Inicialmente, verificou-se que a diferença nos percentis para a primeira questão, "Me dê a boneca que você gosta de brincar" foi estatisticamente significativa, t (98) =10,882, 
$p<0,0001$. Para a segunda questão, também se verificou uma diferença estatisticamente significativa, $t(98)=7,011, p<0,0001$. De igual modo, verificaram-se diferenças estatisticamente significativas para a terceira questão, $\mathrm{t}(98)=6,317, \mathrm{p}<0001$, a quarta questão, $t(98)=16,620, p<0001$, para a quinta questão, $t(98)=27,414, p<0001$, para a sexta questão, $t(98)=27,414, p<0001$, para a oitava questão, $t(98)=9,644, p<0001$ e para a nona e última questão, $t(98)=10,264, p<0001$. Portanto, todos os percentis foram estatisticamente diferentes.

Tabela 2. Respostas à tarefa experimental considerando apenas crianças brancas $(n=48)$

\begin{tabular}{|c|c|c|c|c|c|c|}
\hline & \multicolumn{2}{|c|}{ Branca } & \multicolumn{2}{|c|}{ Negra } & \multicolumn{2}{|c|}{ Total } \\
\hline & $\mathbf{N}$ & $\%$ & $N$ & $\%$ & $N$ & $\%$ \\
\hline Me dê a boneca que você gosta de brincar & 42 & $87,5 \%$ & 6 & $12,5 \%$ & 48 & $100 \%$ \\
\hline Me dê a boneca boa & 36 & $75 \%$ & 12 & $25 \%$ & 48 & $100 \%$ \\
\hline Me dê a boneca má & 12 & $25 \%$ & 36 & $75 \%$ & 48 & $100 \%$ \\
\hline Me dê a boneca que tem uma cor legal & 45 & $93,8 \%$ & 3 & $6,3 \%$ & 48 & $100 \%$ \\
\hline Me dê a boneca que parece com uma criança branca & 47 & $97,9 \%$ & 1 & $2,1 \%$ & 48 & $100 \%$ \\
\hline Me dê a boneca que parece com uma criança de cor & 2 & $4,2 \%$ & 46 & $95,8 \%$ & 48 & $100 \%$ \\
\hline Me dê a boneca que parece com uma criança negra & - & - & 48 & $100 \%$ & 48 & $100 \%$ \\
\hline Me dê a boneca que parece com você & 48 & $100 \%$ & - & - & 48 & $100 \%$ \\
\hline Me dê a boneca que você faria atividades para nota & 42 & $87,5 \%$ & 6 & $12,5 \%$ & 48 & $100 \%$ \\
\hline
\end{tabular}

A Tabela 2 mostra todos os resultados das perguntas feitas às as crianças brancas, totalizando 48 crianças. Analisando as questões apresentadas vemos que, a maioria das crianças brancas teve preferência pela boneca de sua cor, bem como uma perspectiva negativa frente a crianças negras ao reportá-las como aquelas menos legais e más. Além disso, indica ainda uma preferência por envolvimento com crianças do seu próprio grupo racial, ao eleger elas para brincar e fazer atividades para nota. Não obstante, não é possível inferir de forma generalizada qual a concepção das crianças sobre os grupos raciais de fato, bem como, afirmar sua disposição para interagir socialmente com outros grupos. Desse modo, torna-se necessário ampliar essa investigação a fim de melhor conhecer as atitudes e preconceitos frente a grupos raciais distintos.

Tabela 3. Respostas à tarefa experimental considerando apenas crianças negras $(\mathrm{n}=51)$

\begin{tabular}{lcccccc}
\hline & \multicolumn{2}{c}{ Branca } & \multicolumn{2}{c}{ Negra } & \multicolumn{2}{c}{ Total } \\
\cline { 2 - 7 } & $\boldsymbol{N}$ & $\mathbf{\%}$ & $\boldsymbol{N}$ & $\mathbf{\%}$ & \multicolumn{1}{c}{$\boldsymbol{N}$} & $\boldsymbol{\%}$ \\
\hline Me dê a boneca que você gosta de brincar & 44 & $86,3 \%$ & 7 & $13,7 \%$ & 51 & $100 \%$ \\
Me dê a boneca boa & 42 & $82,4 \%$ & 9 & $17,6 \%$ & 51 & $100 \%$ \\
Me dê a boneca má & 11 & $21,6 \%$ & 40 & $78,4 \%$ & 51 & $100 \%$ \\
Me dê a boneca que tem uma cor legal & 47 & $92,2 \%$ & 4 & $7,8 \%$ & 51 & $100 \%$ \\
Me dê a boneca que parece com uma criança branca & 49 & $96,1 \%$ & 2 & $3,9 \%$ & 51 & $100 \%$ \\
Me dê a boneca que parece com uma criança de cor & 1 & $2 \%$ & 50 & $98 \%$ & 51 & $100 \%$ \\
Me dê a boneca que parece uma criança negra & - & - & 51 & $100 \%$ & 51 & $100 \%$ \\
Me dê a boneca que parece com vocêy & 36 & $70,6 \%$ & 15 & $29,4 \%$ & 51 & $100 \%$ \\
Me dê a boneca que você faria atividades para nota & 43 & $84,3 \%$ & 8 & $15,7 \%$ & 51 & $100 \%$ \\
\hline
\end{tabular}


Pág 41

0 estudo de Clark e Clark (1947) encontrou em seus resultados que a maioria das crianças negras preferiu as bonecas brancas de um modo geral. Podemos dizer que nossos resultados corroboram aqueles, mas se encontraram níveis maiores de preferência pela cor branca entre as crianças paraibanas.
A Tabela 3 mostra todos os resultados das perguntas feitas às as crianças negras que no total são 51 crianças. Analisando a tabela percebemos que as respostas das crianças negras entrevistadas têm uma predileção pela cor branca, demonstrando positivamente todas as alternativas ligadas. A questão "Me dê à boneca boa" (82,4\%) e, também, "Me dê à boneca má" (78,4\%), nos chama a atenção, pois a boneca de cor branca foi escolhida pela maioria das crianças negras como boa, associando o que é bom a pessoa de cor branca, levando a reflexão da visão que as crianças tem sobre o que é mau e ruim está associado a cor negra.

Nas questões "Me dê à boneca que tem uma cor legal", fica claro a influência do branqueamento na vida social e escolar das crianças, pois $92,2 \%$ escolheram a boneca branca, assim como na última questão, as crianças consideram que as pessoas de a cor branca eram mais legais. Apesar de a cor negra ser considerada inferior, todas as crianças identificaram-se como sendo negra. Como as amostras apresentadas nas Tabelas 2 e 3 são pequenas decidiu-se por não realizar os testes inferenciais $(t)$ para os percentuais destes grupos.

Conforme se observa as crianças tendem a fazer uma associação negativa com a cor negra demonstrada através de aspectos relacionados à discriminação e preconceito. Os dados da tabela mostram a realidade do que ocorre nas escolas brasileiras, uma completa falta de identificação com a raça negra. Os resultados verificados vão na direção das afirmações de Fernandes (1978) e França e Monteiro (2011) a respeito da perda da identidade dos negros brasileiros, expressa pela negação da própria e da busca do branqueamento.

Por meio desse estudo, pretendeu-se analisar a preferência racial para o grupo de pertença e para outro grupo em crianças brancas e negras de quatro a seis anos. Verificamos que as crianças categorizaram corretamente os grupos raciais, indicando que em média $97 \%$ das crianças entre 4 e 6 anos de idade são capazes de categorizar os grupos raciais estudados, assim como demonstrar preferências pela cor branca, considerando tanto a amostra total (Tabela 1) como os grupos divididos por cor da pela das crianças, sejam as brancas (Tabela 2) e negras (Tabela 3).

0 estudo de Clark e Clark (1947) encontrou em seus resultados que a maioria das crianças negras preferiu as bonecas brancas de um modo geral. Podemos dizer que nossos resultados corroboram aqueles, mas se encontraram níveis maiores de preferência pela cor branca entre as crianças paraibanas. Enquanto no primeiro estudo a maioria preferiam a boneca branca para brincar (67\%), diziam que essa cor era a mais legal (60\%), e que as bonecas negras pareciam más (50\%); no segundo estudo os percentuais indicaram, que as crianças negras preferiram as bonecas brancas para brincar (86,3\%), diziam que elas tinham uma cor legal $(92,2 \%)$, e que bonecas negras pareciam más (78,4\%).

Chama atenção ainda o fato de que mesmo em contextos históricos distintos, com um maior avanço no diálogo a respeito da temática do preconceito racial, além do desenvolvimento de leis e políticas de combate ao mesmo, é prevalente a preferência pela cor branca. No contexto brasileiro verifica-se que o racismo tem se manifestado, por vezes, de forma velada, impedindo a mobilização dos negros em torno dos seus direitos civis. As crianças negras sofrem com o conflito de não querem identificar-se com um grupo percebido desfavoravelmente (França \& Monteiro, 2011; Corenblum et al., 1997). 
Pág 42

Os resultados verificados vão na direção aos achados de Oliveira (1998) relativos à negação das ascendências negras pelas crianças negras e mulatas e as pesquisas desenvolvida por Milner (1973, 1993) sobre a negação da pertença étnica em crianças paquistanesas e indiana na Inglaterra, relacionada com o status superior de cor branca para os indivíduos daquela sociedade.
Como afirma Katz (1983), a identidade racial pressupõe o conhecimento que o mundo social é organizado em grupos raciais. Com base nos resultados aqui encontrados, podemos atestar que a maioria das crianças entre 4 e 6 anos, percebe que existem categorias raciais diferenciadas e que esta percepção aumenta com a idade.

Os nossos resultados também indicaram uma tendência ao branqueamento na preferência das crianças, ou seja, $86,3 \%$ das crianças negras preferem brincar com a boneca branca, e 92,2\% considera a boneca branca mais legal que a negra. Do mesmo modo que as crianças brancas escolheram com a boneca branca para brincar $87,5 \%$ e 93,8\% acreditam que a boneca branca é a mais legal. Sob esse aspecto, o estudo confirma o de França e Monteiro (2002), em que 60\% das crianças negras e $40 \%$ das crianças mulatas apresentaram uma tendência para o branqueamento quando diante da auto identificação, também corroborando estudos prévios (Fernandes et al., 2008; França \& Monteiro, 2011; Máximo et al., 2012; Silva et al., 2002). No entanto, no presente estudo verificou-se que $85,9 \%$ das crianças responderam que preferiam fazer atividades para nota com as bonecas brancas, um percentual bem mais alto do que aquele encontrado por França e Monteiro (2011): 69\%. 0 que por sua vez corrobora a atribuição de capacidade intelectual aos brancos em detrimento dos negros (Bento, 2002; Carneiro, 1998; Fernandes et al., 2008).

Os resultados verificados vão na direção aos achados de Oliveira (1998) relativos à negação das ascendências negras pelas crianças negras e mulatas e as pesquisas desenvolvida por Milner $(1973,1993)$ sobre a negação da pertença étnica em crianças paquistanesas e indiana na Inglaterra, relacionada com o status superior de cor branca para os indivíduos daquela sociedade.

Podemos considerar que apenas as crianças brancas apresentaram identidade racial positiva, visto que são elas que identificam como brancas. Relacionando com pesquisas encontradas por Corenblum e Annis (1993) que estas crianças apresentam congruência entre seus afetos e as avaliações que fazem do próprio grupo, visto que sua autoestima elevada faz com que afirmem sua identidade.

Uma vez que a auto identificação é construída em um contexto social, mudanças no contexto, na auto identificação podem ocorrer, e esta podem ter resultados sobre a preferência, como foi demonstrado anteriormente (Asher \& Allen, 1969) nas quais mudanças na auto identificação e na preferência de crianças negras norte-americanas coincidiu com a expressão do movimento negro nos EUA. Assim, acreditamos que esse quadro de preferências raciais das crianças negras brasileiras pode ser revertido.

Como todo empreendimento científico, este também não está isento de limitações. Destaca-se como a principal, ter contado com crianças de apenas uma região, especificamente do Nordeste brasileiro, de uma cidade do estado da Paraíba. Além do mais, não se contou com uma amostra aleatória de participantes. Isto, por suposto, impede que os dados da presente pesquisa sejam extrapolados para outras crianças de Alagoa Grande. No entanto, ressalta-se que outras pesquisas podem mostrar índices igualmente preocupantes de preconceito racial.

\section{Considerações finais}

O preconceito e a discriminação racial são sem dúvida, um grande desafio para as escolas e os educadores do Brasil. Para compreender como ocorre o preconceito entre as crianças da educação infantil no desenvolvimento da identificação racial e 
suas preferências foi utilizado um experimento com base no estudo de dois psicólogos, Clark e Clark (1947), a utilização desse experimento se deu pelo fato da utilização de bonecas (os) em seu desenvolvimento.

A pesquisa comprovou um índice de preconceito alto entre crianças do município paraibano, confirmando os achados do casal Clark mais de 50 anos do estudo seminal. Nesses termos, é imprescindível que o preconceito seja debatido em sala de aula, para que isso aconteça o professor deve estar preparado e utilizar estratégias criativas para abordar o tema por meio de brincadeiras, roda de conversas e atividades que levem os alunos a colocar-se no lugar do outro, dando bons exemplos dos negros que foram responsáveis pelas muitas conquistas do nosso país.

Por fim, é oportuno que esta pesquisa seja replicada em outras regiões do Brasil, buscando verificar se a preferência pela cor branca se repete. Estes e outros esforços podem ser úteis para um programa de combate ao preconceito racial entre as crianças brasileiras.

\section{Referências}

Aboud, F. (1998). The developmental psychology of racial prejudice. Transcultural Psychiatric Research Review, 30, 229-242. doi: http://dx.doi.org/10.1007/978-3-030$12228-72$

Allport, G. W. (1954). The nature of prejudice. Reading, MA: Addison-Wesley.

APA. (2015). American Psychological Association. Glossary of psychological terms. Recuperado em: http://www.apa.org/research/action/glossary.aspx?tab=17

Aranha, M.L.A. (1993). Maquiavel - A lógica da força. São Paulo: Moderna.

Asher, S. R, \& Allen, V. L. (1969). Racial preference and social comparison processes. Journal of Social Issues, 25, 157-167. doi: http://dx.doi.org/10.1111/j.1540-4560.1969. tb02584

Brown, R. (2010). Prejudice: It's social psychology. UK: Wiley-Blackwell.

Bento, M. A. S. (2002). Branqueamento e branquitude no Brasil. In I. Carone \& M. A. S. Bento (Eds.). Psicologia social do racismo: Estudos sobre branquitude e branqueamento no Brasil (pp. 25-57). Petrópolis: Vozes.

Carneiro, M. L. T. (1998). 0 racismo na história do Brasil: Mito e realidade. São Paulo: Ática.

Clark, K. B., \& Clark, M. P. (1947) Racial identification and preference in negro children. In H. Proshansky \& B. Seidenberg (Eds.), Basic Studies in Social Psychology (pp. 308317). New York: Holt Rinehart and Winston.

Corenblum, B., \& Annis, R. C. (1993). Development of racial identity in minority and majority children: An affect discrepancy model. Canadian Journal of Behavioral Science, 19, 254-265. doi: http://dx.doi.org/10.1037/h0078858

Junior, H. S., Bento, M. A. S., \& Carvalho, S. P. (2012). Educação infantil e práticas promotoras de igualdade racial. São Paulo: Centro de Estudos das Relações de Trabalho e Desigualdades - CEERT: Instituto Avisa lá - Formação Continuada de Educadores.

Fanon, F. (2008). Pele negra máscaras brancas. Rio de Janeiro: Editora Fator.

Fernandes, S.C.S., Almeida, S.S.M., \& Nascimento, C.B.S. (2008). Análise do preconceito racial em uma amostra de crianças brancas de 5 a 8 anos de idade. PSICO, Porto Alegre, 39, (4), 441-447. Recuperado em: https://dialnet.unirioja.es/servlet/ articulo?codigo $=5161537$

Fernandes, F. (1978). A integração do negro na sociedade de classes. São Paulo: Ática.

França, D. X., \& Monteiro, M. B. (2002). Identidade racial e preferência em crianças brasileiras de 5 a 10 anos. Psicologia, 16(2), 293-323. doi: http://dx.doi.org/10.17575/ rpsicol.v16i2.482 
França, D.X., \& Monteiro, M. B. (2011). Identidade racial e atitudes para o próprio e outro grupo em crianças. In S. C. S. Fernandes, C. E. Pimentel, V. V. Gouveia, \& J. L. Álvaro. (Eds.). Psicologia social: perspectivas atuais e evidências empíricas (p. 86-113). São Paulo: Casa do Psicólogo.

Fanon, F. (2008). Pele negra, máscaras brancas. Bahia: Editora Edufba.

Garcia, C. (setembro de 2005). 120 Barbies são vendidas por minuto. Folha de São Paulo, São Paulo.

Guimarães, A.S.A. (2004). Preconceito de cor e racismo no Brasil. Revista de Antropologia, 47(1), 9-43. doi: http://dx.doi.org/10.1590/S0034-77012004000100001

Hirschefeld, A. (1996). Race in making: Cognition, culture and the child's construction of human kinds. Massachusetts. A Bradford Book.

Katz, P.A. (1976). The acquisition of racial attitudes in children. In P.A. Katz (Ed.), Towards the elimination of racism (pp. 125-154). New York: Pergamon Press.

Katz, P.A. (1983). A review of recent research in children's racial attitude acquisition. In L. Katz (Ed.), Current topics in early childhood education (pp. 17-54). Norwood, NJ: Ablex.

Levy, S.R., Rosenthal, L., \& Herrera-Alcazar, A. (2010). Racial and ethnic prejudice among children. In J.L. Chin (Ed.), The psychology of prejudice and discrimination (pp. 37-50). Westport, Connecticut: Praeger.

Lima, M.E.O., \& Vala, J. (2004). As novas formas de expressão do preconceito e do racismo. Estudos de Psicologia (Natal), 9(3), 401-411. doi: http://dx.doi.org/10.1590/ $\underline{\mathrm{S} 1413-294 \times 2004000300002}$

Máximo, T.A.C., Larraian, L.F.C., Nunes, A.L.L., \& Lins, S.L. (2012). Processos de identidade social e exclusão racial na infância. Psicologia em Revista (Online), 18, 507-526. doi: http://dx.doi.org/10.5752/P.1678-9563.2012v18n3p507

Milner, D. (1973). Racial identification and preference in black British children. European Journal of Social Psychology, 3, 281-295. doi: http://dx.doi.org/10.1002/ ejsp.2420030307

Milner, D. (1993). Children and race: Ten years ago. London: Alan Sutton.

Nelson, T.D. (2009). The handbook of prejudice, stereotyping, and discrimination. UK: Psychology Press.

Oliveira, I. (1998). As desigualdades raciais vistas pelas crianças e pelos jovens. Dissertação de Mestrado Não-Publicada em Psicologia Escolar e do Desenvolvimento Humano. Instituto de Psicologia, Universidade de São Paulo, São Paulo.

Paré, M. L. (2000). Autoimagem e autoestima na criança negra: Um olhar sobre o seu desempenho escolar. Dissertação de Mestrado Não-Publicada em Educação. PUC/Rio grande do Sul. Porto Alegre.

Pérez-Nebra, A.R., \& Jesus, J.G. (2011). Preconceito, estereótipo e discriminação. In C.V. Torres \& E.R. Neiva (Eds.), Psicologia social: Principais temas e vertentes (pp. 219237). Porto Alegre, RS: ArtMed.

Ramsey, P. G. (1987). Young children's thinking about ethnic differences. In J. Phinney \& M. J. Rotherman, (Eds.), Ethnic socialization of children (pp. 32-55). Beverly Hills: Sage Publications.

Rodrigues, A., Assmar, E.M.L., \& Jablonski, B. (2012). Psicologia social. Petrópolis: Vozes.

Roland, E. (2001). Gênero e raça e a promoção da igualdade. Brasília: TEM Acessoria Internacional.

Secretaria de Educação Fundamental de Brasil (1997). Parâmetros Curriculares Nacionais: apresentação dos temas transversais, ética. Secretaria de Educação Fundamental-Brasília: MEC/SEF.

Silva, P., Pereira, A., \& Camino, L. (2002). O desenvolvimento racial e o processo de branqueamento em crianças. In: VI CCHLA. Conhecimento em Debate. [CD-ROM]. João Pessoa: Editora da Universidade Federal da Paraíba. 
Silva, L. R. (2018). Não me chame de mulata: uma reflexão sobre a tradução em literatura afrodescendente no Brasil no par de línguas espanhol-português. TrabaIhos Em Linguística Aplicada, 57(1), 71-88. Recuperado de https://periodicos.sbu. unicamp.br/ojs/index.php/tla/article/view/8651618

Tajfel, H. (1978). Social categorization, social identity and social comparison. In: H. Tajfel. (Ed.). Differentiation between groups (pp. 61-76). London: Academic Press.

Turra, C., \& Venturi, G. (1995). Racismo cordial: A mais completa análise sobre preconceito de cor no Brasil. São Paulo: Ática.

Weschenfelder, V. I., \& Silva, M. L. D. (2018). A cor da mestiçagem: o pardo e a produção de subjetividades negras no Brasil contemporâneo. Análise Social, (227), 308-330. doi: http://dx.doi.org/10.31447/AS00032573.2018227.03 